\title{
ANALYSIS OF CONSEQUENCE APPLIED TO HYPOTHETICAL SCENARIOS OF ACCIDENTS WITH INDUSTRIAL LEAKAGE OF HYDROGEN SULFIDE USING ALOHA 5.4.4® SOFTWARE
}

\author{
H. Silva Júnior ${ }^{1}$, N.L. Santos ${ }^{2}$, G.A. Fernandes ${ }^{3}$, T.J. Lopes ${ }^{4}$ \\ ${ }^{I}$ School of Chemistry and Food, Federal University of Rio Grande - FURG, Brazil \\ ${ }^{2}$ School of Chemistry and Food, Federal University of Rio Grande - FURG, Brazil \\ ${ }^{3}$ Institute of Mechanical Engineering, Federal University of Itajubá - UNIFEI, Brazil \\ ${ }^{4}$ School of Chemistry and Food, Federal University of Rio Grande - FURG, Brazil
}

\begin{abstract}
Accidents with leaks of industrial toxic gases such as hydrogen sulfide, a chemical agent found in oil refineries, are increasingly a concern of enforcement agencies. Accidents with hydrogen sulfide leaks can expose workers and the community to direct contact with the agent, leading to mild respiratory irritation and even death. Thus, the responsibility on the part of the companies with the handling of the same is the guideline of several studies to avoid accidents. Using as a method, simulations to evaluate and qualify possible risks of leakage in refinery installations. The study resulted in the classification of scenario simulations regarding the hazard it offers and the consequence analysis with gas cloud modeling performed by the ALOHA 5.4.4® software. These data were also treated in STATISTICA 8.0 software with a focus on predictions using determinant variables at the time of the leak.
\end{abstract}

Keywords: Stink Damps, Statistical Analysis, Oil Refineries, Environmental Impact, Toxic Substance.

\section{INTRODUCTION}

Industries are constantly using new resources to facilitate their processes. And a fact that is seen at all times is assigned to the energetic forms used. Being the main forms of energy: thermal, mechanical, electrical, hydraulic and nuclear. From this, it is seen that there are several alternatives to establish an energy matrix in a given location, depending only on the availability of raw material to be used. Thus, it is appropriate to speak of the oil that is today the most widely used fuel in the world's matrices, which, compared to coal, has a higher heat capacity, besides being easily transported by being liquid $[5,11]$.

In this context, it can be seen that oil has a fundamental role in the world's energy matrixes. And its use is related to all the fundamental processes that involve hydrocarbons [5]. In fact, oil is an extremely differentiated raw material, since the number of components reaches more than 40 thousand substances. And a large part of the petroleum fractions obtained in the refining process is used in combustion processes to generate energy or to move loads and people. However, during the process of purifying the natural gas and the gaseous products of a refinery, a mixture of several gases is found that poorly processed leaks and explosions in contact with the oxygen gas $[9,11,14]$.

And one of the gases involved in refining is hydrogen sulfide gas $\left(\mathrm{H}_{2} \mathrm{~S}\right)$, an agent of the order of high flammability, colorless, and extremely toxic. Its autoignition temperature is $260^{\circ} \mathrm{C}$, while its low explosion limit is of the volume order of $4.3 \%$ in air. Since hydrogen sulfide $\left(\rho_{2} \mathrm{~S}=1.46 \mathrm{~kg} / \mathrm{m}^{3}\right)$ is denser than air $\left(\rho_{\mathrm{ar}}=1.2754 \mathrm{~kg} / \mathrm{m}^{3}\right)$, it condenses in liquid form at a temperature of $-62^{\circ} \mathrm{C}$, which in contact with water and organic compounds is partially solubilized at the conditions of 1 atm $[8,10]$.

The concentration of hydrogen sulfide in the air must be analyzed at all times, especially when it involves the direct contact of humans in these processes. This, due to its toxicity it is able to hinder the breath in minutes, leading to its death. In the activities or operations in which workers are exposed to the hydrogen sulfide, the characterization of unhealthiness will occur when the limits of constant tolerance proposed by the NR-15 term are exceeded, whose tolerance limit is $8 \mathrm{ppm}$ or $12 \mathrm{mg} / \mathrm{m}^{3}$, which is a validated concentration average for work period of up to 48 hours per week. If the case exceeds the level of 16 ppm per day of 8 hours, a serious and imminent risk situation shall be considered, and due compensation shall be taken in accordance with what is stated in Art. 60 of the CLT $[6,10]$.

Accidents with hydrogen sulfide in the industrial branches are directly linked to their toxic action in humans. These accidents are most often caused by their chemical reaction in metals. Therefore, the corrosion associated with $\mathrm{H} 2 \mathrm{~S}$ can be defined as total, partial, superficial or structural deterioration of the materials, causing the rupture of industrial equipment, resulting in leaks. Having as consequences: intoxications, explosions and death of workers $[2,6,9]$. 
Considering the high risk of hydrogen sulfide gas, the United States Public Safety Agency (OSHA - Occupational Safety and Health Administration) reported 1480 mentions on direct or indirect $\mathrm{H}_{2} \mathrm{~S}$ contamination worldwide in the period 1984-1994. This shows due concern with all the industrial branches that involve the same. Management is required in these situations. Featuring thus, its risks and possible scenarios of accidents. Consequently, reducing levels of accidental risk [10].

The main branches that involve the use of $\mathrm{H}_{2} \mathrm{~S}$ in their process, such as refineries and sewage treatment units, must have an intrinsic correlation with environmental organs, since the respective ones are directly related to the use of effluents. Being obliged to have requirements for their compliance with environmental guidelines, as well as establishing the conditions and standards for effluent releases, and other measures, guided by CONAMA Resolution number 357 dated 03/18/2005. Which provides environmental risk analysis measures, which are studied with a view to work safety, are important mechanisms of diagnosis and planning in the management of safety in the plant [2,3]. For that, in the literature there are works that use the software ALOHA as support in these plans, as: Bhattacharya and Kumar (2015), carried out a case study and validated with the simulations made in ALOHA. Tseng, $\mathrm{Su}$ and Kuo (2012) who studied the leakage of toxic substances into a complex. AndKavishwar and Chatpalliwar (2013) who evaluated the consequence analysis with ammonia gas leakage.

Considering the above, the present work studied the application of the leakage consequence analysis method used for hazard evaluations, which was applied Areal Locations of Hazardous Atmospheres - ALOHA gas leakage modeling software and STATISTICA software for the prediction of results with the main variables in question, which resulted in the knowledge of the possible causes of leaks at critical points of the installations and the consequences of the flow of hydrogen sulfide, together with its effects on vulnerable areas, where workers and the community are exposed.

\section{METHODOLOGY}

The research was carried out in an exploratory manner, aiming to contextualize a little explored problem of work safety in the oil refining industries, starting from the development of a hypothetical case study. The research was operationalized observing the methodology of the manual of the study of industrial risks operating in Brazil. This manual was instrumental in applying the methods of consequence analysis.

The method of the risk analysis manual presents the reference system for the acquisition of environmental licensing of activities, but since it is a research aimed at the study of a specific risk of the refineries used under the focus of work safety, the analyzes and documentary requirements for licensing as recommended in the manual. The development of the consequence analysis study of the petroleum industry facilities was carried out observing the following steps: characterization of the place; simulation with the ALOHA software to analyze the toxic clouds with the characteristics of the studied region; method used to evaluate the dispersion of the chemical; classifications to which the installation risk in the simulation fits; analysis of consequences; preliminary study of leakage simulations with hydrogen sulfide; statistical treatment; discussion of results.

\subsection{Characterization of the Study Place}

At this stage, the meeting of data on the characteristics of the place was presented, considering its constructive aspects and its qualification, besides the peculiarities of the region and climatic conditions. The characterization of the area provided results such as the diagnosis of the interfaces between the simulation scenario and the studied variables.

\subsection{Simulation with the ALOHA Software for}

\section{Analysis of Toxic Clouds with the Characteristics of} the Studied Region

The software was developed by the US Environmental Protection Agency (EPA). The version available on the worldwide computer network used for this research was version 5.4.4. The software is an engineering tool to evaluate the dispersion, explosion or flammability properties of a chemical and analyzes the impact of toxicity, flammability and explosiveness on atmospheric leaks, enabling the modeling of clouds from established scenarios. To do this, it was necessary to determine some input data based on leakage rates considered to be dangerous for the inspection agencies.

The data on the hydrogen sulfide storage vessel was attached. Based on an analysis of the Chemical Safety Data Sheets provided by companies on their respective places, a data collection was made, such as: it is stored in cylinders with an average length of $0.5 \mathrm{mx} 1.0 \mathrm{~m}$, it is found about $70 \%$ of its volume on average in the cylinders. It was found on the Alibaba Group site containers for sale for the storage of hydrogen sulfide, in which the conclusion of cylinder size was removed.

By adding the size of the pouring hole and at what height the hole is. It has been taken into account the recurrence of leakage, and as in the case of hydrogen sulfide is by corrosion or external factors, then the hole is small. After filling in all the data for the simulation, you can check the summary text to confirm the attached data. One can then observe the radial graphs in which shows the dispersion of the toxic cloud of the gas according to the AEGLs in analysis of the substance and the mass flow. 


\subsection{Method Used to Evaluate the Dispersion of}

\section{Chemical Substance}

The leak was modeled in steady state. The model used to describe the dispersion of each cloud is based on a Gaussian dispersion model developed by Palazzi that describes the short-term steady-state release behavior [12]. This model is described in Equation 1:

$$
\begin{gathered}
C(x, y, z, t)= \\
\left\{\begin{array}{c}
\frac{\chi}{2}\left[\operatorname{erf}\left(\frac{x}{\sigma_{x} \sqrt{2}}\right)-\operatorname{erf}\left(\frac{x-U_{t}}{\sigma_{x} \sqrt{2}}\right)\right]\left(t \leq t_{r}\right) \\
\frac{\chi}{2}\left[\operatorname{erf}\left(\frac{x-U\left(t-t_{r}\right)}{\sigma_{x} \sqrt{2}}\right)-\operatorname{erf}\left(\frac{x-U_{t}}{\sigma_{x} \sqrt{2}}\right)\right]\left(t_{r}<t<\infty\right)
\end{array}\right.
\end{gathered}
$$

Where: $\sigma_{x}, \sigma_{y}$ and $\sigma_{z}$ are dispersion parameters; $t r$ is the duration of the leak; $U$ wind-related variable.

The term $\chi$ represents a Gaussian distribution from a wellknown point source and steady state, seen in Equation (2):

$$
\chi(x, y, z, t)=\left(\frac{Q(t)}{U}\right) g_{y}(x, y) g_{z}(x, z)
$$

$g_{y}$ is calculated by Eq. (3).

$$
g_{y}(x, y)=\frac{1}{\sqrt{2 \pi} \sigma_{y}(x)} \exp \left[-\frac{1}{2}\left(\frac{y}{\sigma_{y}(x)}\right)^{2}\right]
$$

$g_{z}$ is calculated by Eq. (4).

$$
\begin{aligned}
g_{z}(x, z) & =\frac{1}{\sqrt{2 \pi} \sigma_{z}(x)}\left\{\exp \left[-\frac{1}{2}\left(\frac{z-h_{s}}{\sigma_{z}(x)}\right)^{2}\right]\right. \\
& \left.+\exp \left[-\frac{1}{2}\left(\frac{z+h_{s}}{\sigma_{z}(x)}\right)^{2}\right]\right\}
\end{aligned}
$$

where $h_{s}$ is the height of the launch.

\subsection{Classification of Installations}

The classification of industrial risk of the Brazilian agency allowed to present and fit the risk index of the refinery facilities to the surroundings of the studied industry. The steps for the classification of the industry were: The determination of the mass released accidentally; The determination of the reference mass for hydrogen sulfide; The calculation of the distance factor; Calculation of the hazard factor; The calculation of the risk classification index.

At this stage, data were requested regarding hypothetical installations, such as the capacity of stored hydrogen sulfide, container vessel dimensions and others. All data were collected in studies related to the refining schemes provided by companies in the industry.

\subsection{Consequence Analysis}

The consequences analysis was based on the evaluation of the effects of accidents with leakage of hydrogen sulfide, based on hypothetical scenarios. The evaluation was performed through the results obtained in modeling the leaks provided by the ALOHA software. The objective of this analysis was to identify the distance and impacts of hydrogen sulfide clouds reaching vulnerable areas in case of leakage.

\subsection{Preliminary Study of Leakage Simulations with}

\section{Hydrogen Sulfide}

We performed hypothetical simulations for the knowledge of the program with random values of the variables that determine the dispersion of the toxic cloud. To know the significant factors for the simulation and to define the variables for the statistical treatment.

\subsection{Statistical Treatment}

In the statistical treatment, the predicted values of the variables defined in the previous topic were observed. The software STATISTICA version 8.0 was used to use multiple linear regression, which is a multivariate technique whose main purpose is to obtain a mathematical relationship between one of the studied variables and the rest of the variables that describe the system and reduce a large number of variables to a few dimensions with the minimum loss of information, allowing the detection of the main patterns of similarity. Thus, producing values for the dependent variable, since already having the independent variable can predict results by means of statistical rules. For this, a set of data from the study of the preliminary simulations was used. In that it was observed that the variables found in Table 1 are significant for the dispersion of toxic clouds. The resolution used for analysis $\operatorname{was} 2_{I V}^{8-3}$.

Table 1: Variables used in data processing and their coded levels

\begin{tabular}{|l|l|l|}
\hline \multirow{2}{*}{ Variables } & \multicolumn{2}{|l|}{ Coded Level } \\
\cline { 2 - 3 } & $\mathbf{- 1}$ & $\mathbf{+ 1}$ \\
\hline Wind speed (m/s) & $15 \mathrm{~m} / \mathrm{s}$ & $25 \mathrm{~m} / \mathrm{s}$ \\
\hline Relative humidity (\%) & $40 \%$ & $70 \%$ \\
\hline Temperature (K) & $288.15 \mathrm{~K}$ & $303.15 \mathrm{~K}$ \\
\hline $\begin{array}{l}\text { Cylinder dimensions (diameter } \\
\text { X length) (m) }\end{array}$ & $0.5 \times 1 \mathrm{~m}$ & $1 \times 2 \mathrm{~m}$ \\
\hline $\begin{array}{l}\text { Percent of Chemical Agent in } \\
\text { Cylinder (\%) }\end{array}$ & $30 \%$ & $70 \%$ \\
\hline Diameter of Leak Hole (m) & $0.005 \mathrm{~m}$ & $0.015 \mathrm{~m}$ \\
\hline Cylinder Orifice Height (m) & $0.5 \mathrm{~m}$ & $1.0 \mathrm{~m}$ \\
\hline Climate conditions & Clean & $\begin{array}{l}\text { Partially } \\
\text { Cloudy }\end{array}$ \\
\hline
\end{tabular}

Multiple regression was used in order to predict, in which this model is applied by the software to explain the behavior of the variables of the database being studied. In multiple 
regression, the variable determined is that which has a significant correlation with the variable to be predicted.

\subsection{Discussion of Results}

The evaluation of the results with presentation of the analysis and some proposals for the prevention and control of risks was presented at this stage.

\section{ANALYSIS OF STUDY APPLICATION WITH}

\section{SIMULATIONS}

\subsection{Characterization of the Study Place}

At the stage of the risk analysis we considered a compilation of data on the characteristics of the place studied and climatic aspects. The hypothetical scenario characterization provides a diagnosis of the interfaces between the simulation under analysis and the location of its installation.

\subsection{Classification of Installation Risks}

According to the method of the risk analysis study manual, the classification of the facility will at first allow to categorize the risk to which the vulnerable areas are exposed. It is understood as a vulnerable area, the area around the activity, in which environment, population and workers, are exposed to the effects of accidents. From Equation 5 shows that the industrial risk is directly linked to the intensity of danger and inversely the amount of safeguard. It may be considered by way of risk classification that the hazard may be represented by the amount of hazardous material capable of being accidentally released into the environment and safeguards are combinations of factors which tend to minimize the harmful effects of accidental releases. It considers the main factor safeguarding the distance between the point of release of the hazardous material and the population [4].

$$
\text { RISK }=\frac{\text { DANGER }}{\text { SAFEGUARD }}
$$

Eq. (6) makes it possible to calculate the risk index, which is necessary to classify the risk of the activity.

$$
\mathrm{IR}=\frac{\mathrm{FP}}{\mathrm{FD}}
$$

$\mathrm{IR}=$ risk index

$\mathrm{FP}=$ danger factor

$\mathrm{FD}=$ distance factor

\section{CALCULATION OF THE DISTANCE FACTOR}

To find the IR value, it will be necessary to establish the FP values and the calculation of the distance factor FD in Eq. (7):

$$
\mathrm{FD}=\frac{\mathrm{D}}{50}
$$

$\mathrm{FD}=$ distance Factor

$\mathrm{D}=$ the shortest distance in meters between the release point and the point of interest where vulnerable resources are located $(\mathrm{m})$.

\section{CALCULATION OF THE DANGER FACTOR}

The hazard factor given by Eq. (8) represents a measure of the intensity of the source of risk. The greater the amount of material accidentally released, the greater the danger; therefore the greater the risk.

$$
\mathrm{FP}=\frac{\mathrm{MLA}}{\mathrm{MR}}
$$

FP = danger Factor

MLA $=$ accidentally released mass $(\mathrm{kg})$

$\mathrm{MR}=$ reference mass $(\mathrm{kg})$

The value of MLA is the largest amount of hazardous material capable of participating in an accidental release of a hazardous substance. This release may be caused by ruptures of pipes, components in lines, pumps, vessels, tanks; or by operation error, or uncontrolled reaction or explosion confined or not.

\subsection{Risk Classification}

The IR values for the two plants were classified according to Table 2 [4]:

Table 2: Classification of installations or activities based on the IR Risk Index

\begin{tabular}{|l|l|}
\hline RISK INDEX & RISK CATEGORY \\
\hline IR \# 1 & 1 \\
\hline $1<$ IR \# 2 & 2 \\
\hline $2<$ IR \# 4 & 3 \\
\hline $4<$ IR & 4 \\
\hline
\end{tabular}

Characteristics of the risk category:

-Hazard category 1 corresponds to those facilities/activities that can be considered negligible because they have very small quantities (or not) of dangerous substances in process or storage [4].

-Hazard category 2 corresponds to those facilities/activities that can cause significant damage over distances of up to $100 \mathrm{~m}$ from the place [4].

-Hazard category 3 corresponds to those installations/activities that can cause significant damage over distances between $100 \mathrm{~m}$ and $500 \mathrm{~m}$ from the place [4]. -Hazard category 4 corresponds to those facilities/activities that can cause significant damage over distances of more than $500 \mathrm{~m}$ from the place [4].

\subsection{Consequences Analysis}

Proceeding to the steps of risk analysis study was started to the consequences analysis with the model of the sulfide gas cloud to know the impact of the leak to the workers, the 
community and the environment. For the quantitative modeling and simulation of the scenarios a software of public domain ALOHA was used.

\subsection{Preliminary Study of Simulations of Leakage}

\section{with Hydrogen Sulfide Storage Tank Information}

The cylindrical shaped tank is horizontal; its measures are: diameter equal to $3.15 \mathrm{~m}$, length equal to $11.14 \mathrm{~m}$, total cylinder volume is $86.8 \mathrm{~m} 3$. The same measures were used for all preliminary simulations in the study. Figure 1 shows the graphs, radial and mass flow of their respective simulation as an example, some values of the other simulations will be in Table 3 with some factors.
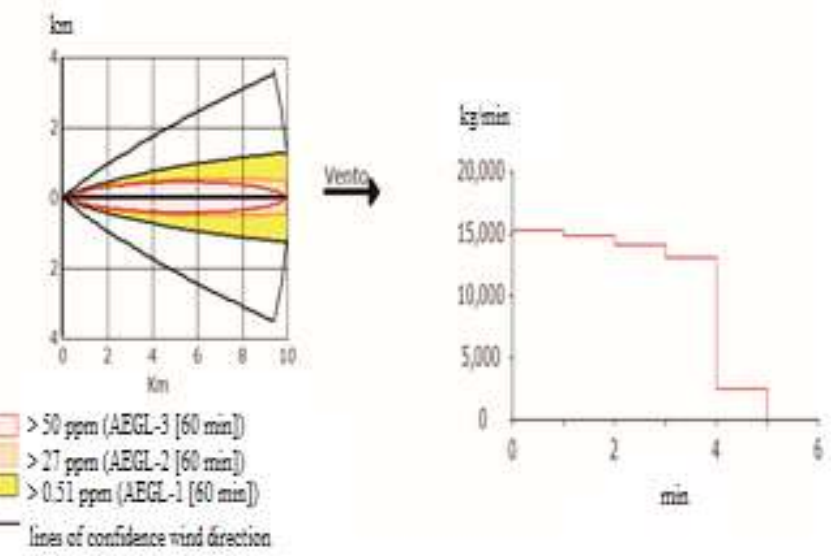

Fig 1: Radial and mass flow graphs of the preliminary simulation 01 .

Table 3: Some factors with maximum and minimum values of preliminary simulations

\begin{tabular}{|l|l|l|}
\hline & $\begin{array}{l}\text { Minimum } \\
\text { value }\end{array}$ & $\begin{array}{l}\text { Maximum } \\
\text { value }\end{array}$ \\
\hline Wind speed (m/s) & 2.5 & 7.5 \\
\hline Relative humidity (\%) & 5 & 99 \\
\hline Temperature (K) & 296.15 \\
\hline $\begin{array}{l}\text { Percent of Chemical Agent in } \\
\text { Cylinder (\%) }\end{array}$ & 87 \\
\hline Diameter of Leak Hole (m) & 0.05 & 0.20 \\
\hline Cylinder Orifice Height (m) & 0 \\
\hline
\end{tabular}

Through preliminary study, it was able to make a compilation of significant variants for the dispersion of toxic cloud. Thus, the data were treated with scenarios consistent with the reality studied, that is, characteristics of the region under analysis with the relevant factors established in the preliminary simulations.

\subsection{Statistical Treatment}

In the evaluation of the hypothetical scenarios, 32 simulations were performed, due to the resolution used in STATISTISCA, made in the ALOHA gas-liquid mixture of $\mathrm{H}_{2} \mathrm{~S}$ software and processed in the STATISTICA software for the prediction of results. The maximum width and maximum length of the toxic cloud were analyzed in their respective scenarios provided in the radial graph of each scenario. Their masses vary according to the different percentages of the phases of the substance present in the container. The location of the pouring hole is in the region of the tank containing the liquid phase. Table 4 presents the main input data for the respective scenarios and Table 5 shows the responses for the three AEGLs, their maximum lengths and their maximum widths.

With the answers of the maximum lengths taken by the graphs. They were treated in STATISTICA software to predict situations. Being treated with two interactions and without interaction. An interaction effect occurs when a relationship between two variables is modified by another variable. In other words, the strength or the sign of a relationship between the two variables is different depending on the value of some other variable. Following are the figs (2)-(3) the contour and Pareto graphs of the AEGL-1 with the maximum length response without interaction (No interactions). And in figs (4)-(5) are represented with two interactions (2-way-interactions).

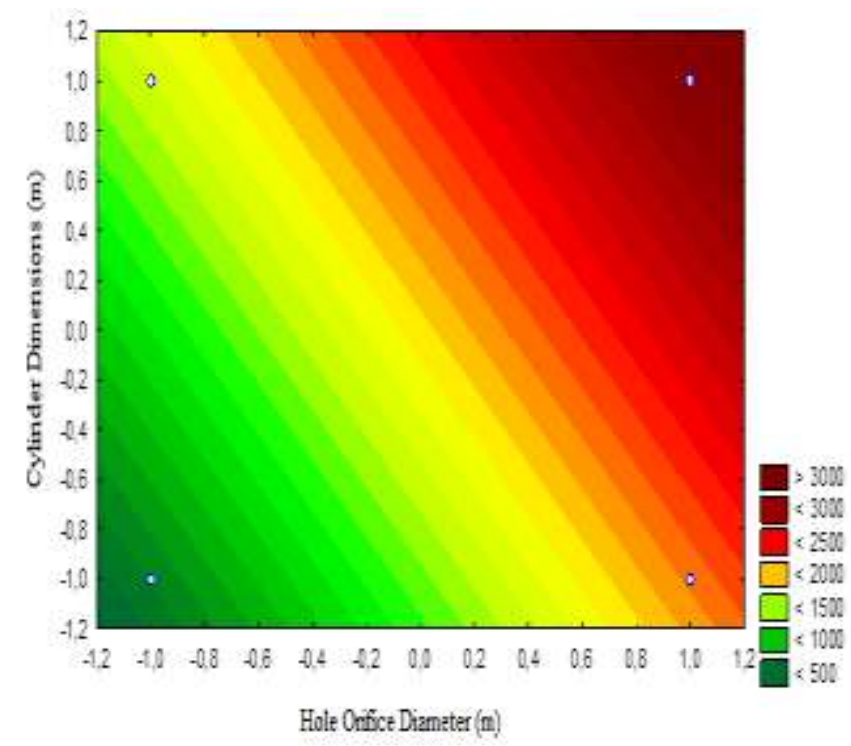

Fig 2: Contour plot with the variables cylinder dimensions and hole orifice diameter.

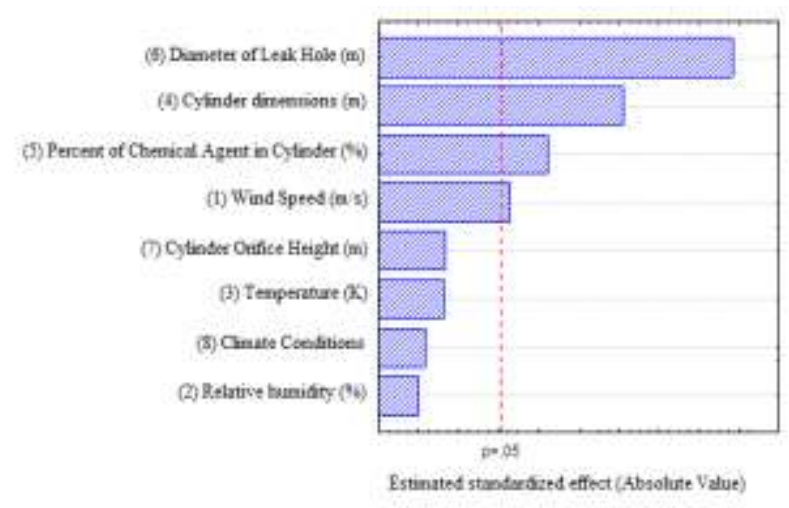

Fig 3: Pareto graph with the significant variables. 


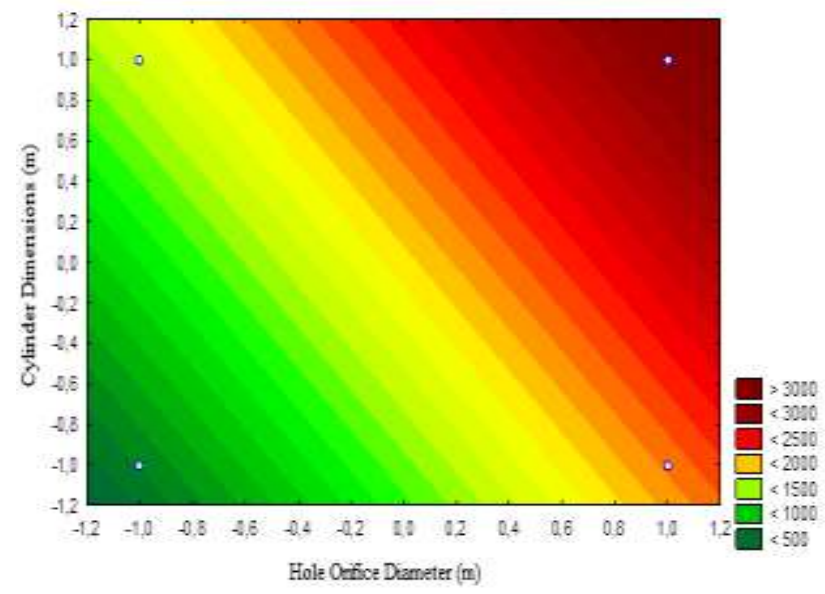

Fig 4: Contour plot with the variables cylinder dimensions and hole orifice diameter

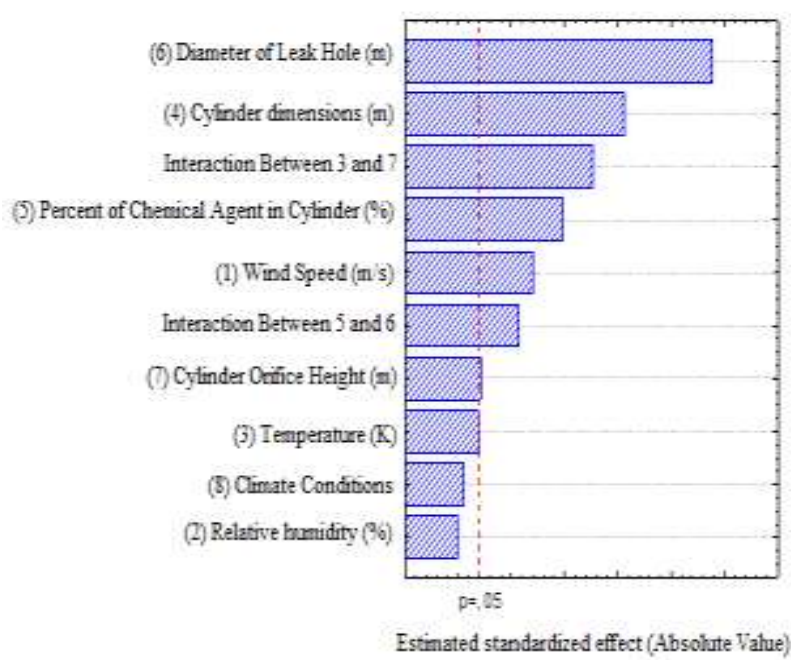

Fig 5: Pareto graph with the significant variables.

Table 4: Input data by leak scenarios in ALOHA software.

\begin{tabular}{|c|c|c|c|c|c|c|c|c|}
\hline \multicolumn{9}{|c|}{ Input data for the leak scenarios } \\
\hline Scenarios & $\begin{array}{l}\text { Wind } \\
\text { speed } \\
(\mathrm{m} / \mathrm{s})\end{array}$ & $\begin{array}{l}\text { Relative } \\
\text { humidity } \\
(\%)\end{array}$ & $\begin{array}{l}\text { Temperature } \\
\text { (K) }\end{array}$ & $\begin{array}{l}\text { Cylinder } \\
\text { dimensions } \\
\text { (m) }\end{array}$ & $\begin{array}{l}\text { Percent of } \\
\text { Chemical } \\
\text { Agent in } \\
\text { Cylinder }(\%)\end{array}$ & $\begin{array}{l}\text { Diameter of } \\
\text { Leak Hole } \\
\text { (m) }\end{array}$ & $\begin{array}{l}\text { Cylinder } \\
\text { Orifice } \\
\text { Height (m) }\end{array}$ & $\begin{array}{l}\text { Climate } \\
\text { conditions }\end{array}$ \\
\hline 01 & 15 & 40 & 288.15 & $0.5 \times 1.0$ & 30 & 0.005 & 0.5 & $\begin{array}{l}\text { Partially } \\
\text { Cloudy }\end{array}$ \\
\hline 02 & 25 & 40 & 288.15 & $0.5 \times 1.0$ & 30 & 0.015 & 1.0 & $\begin{array}{l}\text { Partially } \\
\text { Cloudy }\end{array}$ \\
\hline 03 & 15 & 70 & 288.15 & $0.5 \times 1.0$ & 30 & 0.015 & 1.0 & Clean \\
\hline 04 & 25 & 70 & 288.15 & $0.5 \times 1.0$ & 30 & 0.005 & 0.5 & Clean \\
\hline 05 & 15 & 40 & 303.15 & $0.5 \times 1.0$ & 30 & 0.015 & 0.5 & Clean \\
\hline 06 & 25 & 40 & 303.15 & $0.5 \times 1.0$ & 30 & 0.005 & 1.0 & Clean \\
\hline 07 & 15 & 70 & 303.15 & $0.5 \times 1.0$ & 30 & 0.005 & 1.0 & $\begin{array}{l}\text { Partially } \\
\text { Cloudy }\end{array}$ \\
\hline 08 & 25 & 70 & 303.15 & $0.5 \times 1.0$ & 30 & 0.015 & 0.5 & $\begin{array}{l}\text { Partially } \\
\text { Cloudy }\end{array}$ \\
\hline 09 & 15 & 40 & 288.15 & $1.0 \times 2.0$ & 30 & 0.005 & 1.0 & Clean \\
\hline 10 & 25 & 40 & 288.15 & $1.0 \times 2.0$ & 30 & 0.015 & 0.5 & Clean \\
\hline 11 & 15 & 70 & 288.15 & $1.0 \times 2.0$ & 30 & 0.015 & 0.5 & $\begin{array}{l}\text { Partially } \\
\text { Cloudy }\end{array}$ \\
\hline 12 & 25 & 70 & 288.15 & $1.0 \times 2.0$ & 30 & 0.005 & 1.0 & $\begin{array}{l}\text { Partially } \\
\text { Cloudy }\end{array}$ \\
\hline 13 & 15 & 40 & 303.15 & $1.0 \times 2.0$ & 30 & 0.015 & 1.0 & $\begin{array}{l}\text { Partially } \\
\text { Cloudy }\end{array}$ \\
\hline
\end{tabular}




\begin{tabular}{|c|c|c|c|c|c|c|c|c|}
\hline 14 & 25 & 40 & 303.15 & $1.0 \times 2.0$ & 30 & 0.005 & 0.5 & $\begin{array}{l}\text { Partially } \\
\text { Cloudy }\end{array}$ \\
\hline 15 & 15 & 70 & 303.15 & $1.0 \times 2.0$ & 30 & 0.005 & 0.5 & Clean \\
\hline 16 & 25 & 70 & 303.15 & $1.0 \times 2.0$ & 30 & 0.015 & 1.0 & Clean \\
\hline 17 & 15 & 40 & 288.15 & $0.5 \times 1.0$ & 70 & 0.005 & 0.5 & Clean \\
\hline 18 & 25 & 40 & 288.15 & $0.5 \times 1.0$ & 70 & 0.015 & 1.0 & Clean \\
\hline 19 & 15 & 70 & 288.15 & $0.5 \times 1.0$ & 70 & 0.015 & 1.0 & $\begin{array}{l}\text { Partially } \\
\text { Cloudy }\end{array}$ \\
\hline 20 & 25 & 70 & 288.15 & $0.5 \times 1.0$ & 70 & 0.005 & 0.5 & $\begin{array}{l}\text { Partially } \\
\text { Cloudy }\end{array}$ \\
\hline 21 & 15 & 40 & 303.15 & $0.5 \times 1.0$ & 70 & 0.015 & 0.5 & $\begin{array}{l}\text { Partially } \\
\text { Cloudy }\end{array}$ \\
\hline 22 & 25 & 40 & 303.15 & $0.5 \times 1.0$ & 70 & 0.005 & 1.0 & $\begin{array}{l}\text { Partially } \\
\text { Cloudy }\end{array}$ \\
\hline 23 & 15 & 70 & 303.15 & $0.5 \times 1.0$ & 70 & 0.005 & 1.0 & Clean \\
\hline 24 & 25 & 70 & 303.15 & $0.5 \times 1.0$ & 70 & 0.015 & 0.5 & Clean \\
\hline 25 & 15 & 40 & 288.15 & $1.0 \times 2.0$ & 70 & 0.005 & 1.0 & $\begin{array}{l}\text { Partially } \\
\text { Cloudy }\end{array}$ \\
\hline 26 & 25 & 40 & 288.15 & $1.0 \times 2.0$ & 70 & 0.015 & 0.5 & $\begin{array}{l}\text { Partially } \\
\text { Cloudy }\end{array}$ \\
\hline 27 & 15 & 70 & 288.15 & $1.0 \times 2.0$ & 70 & 0.015 & 0.5 & Clean \\
\hline 28 & 25 & 70 & 288.15 & $1.0 \times 2.0$ & 70 & 0.005 & 1.0 & Clean \\
\hline 29 & 15 & 40 & 303.15 & $1.0 \times 2.0$ & 70 & 0.015 & 1.0 & Clean \\
\hline 30 & 25 & 40 & 303.15 & $1.0 \times 2.0$ & 70 & 0.005 & 0.5 & Clean \\
\hline 31 & 15 & 70 & 303.15 & $1.0 \times 2.0$ & 70 & 0.005 & 0.5 & $\begin{array}{l}\text { Partially } \\
\text { Cloudy }\end{array}$ \\
\hline 32 & 25 & 70 & 303.15 & $1.0 \times 2.0$ & 70 & 0.015 & 1.0 & $\begin{array}{l}\text { Partially } \\
\text { Cloudy }\end{array}$ \\
\hline
\end{tabular}

Table e5: Scenario responses, maximum length and maximum width.

\begin{tabular}{|c|c|c|c|c|c|c|}
\hline \multicolumn{7}{|c|}{ Resolution } \\
\hline & \multicolumn{2}{|l|}{ AEGL-1 $^{(1)}$} & \multicolumn{2}{|l|}{ AEGL-2 ${ }^{(2)}$} & \multicolumn{2}{|l|}{ AEGL-3 ${ }^{(3)}$} \\
\hline $\begin{array}{l}\text { Scenari } \\
\text { os }\end{array}$ & $\begin{array}{l}\text { Maximum length } \\
(\mathrm{m})\end{array}$ & $\begin{array}{l}\text { Maximum } \\
\text { width (m) }\end{array}$ & $\begin{array}{l}\text { Maximum length } \\
(\mathrm{m})\end{array}$ & $\begin{array}{l}\text { Maximum } \\
\text { width }(\mathrm{m})\end{array}$ & $\begin{array}{l}\text { Maximum length } \\
(\mathrm{m})\end{array}$ & $\begin{array}{l}\text { Maximum } \\
\text { width }(\mathrm{m})\end{array}$ \\
\hline 01 & 927 & 127 & 119 & 25.4 & 87 & 25.4 \\
\hline 02 & 1100 & 156 & 138 & 6.5 & 101 & 6.5 \\
\hline 03 & 1400 & 194 & 179 & 13 & 130 & 6.5 \\
\hline 04 & 705 & 93.6 & 92 & 10.4 & 67 & 10.4 \\
\hline 05 & 1600 & 220 & 197 & 26 & 144 & 13 \\
\hline
\end{tabular}




\begin{tabular}{|l|l|l|l|l|l|l|}
\hline 06 & 781 & 109 & 101 & 15.6 & 74 & 15.6 \\
\hline 07 & 1000 & 142 & 131 & 13 & 96 & 13 \\
\hline 08 & 1200 & 168 & 152 & 13 & 111 & 13 \\
\hline 09 & 888 & 114.2 & 114 & 12.7 & 83 & 6.34 \\
\hline 10 & 2700 & 360 & 309 & 26 & 226 & 26 \\
\hline 11 & 3200 & 440 & 403 & 52 & 293 & 26 \\
\hline 12 & 676 & 98.8 & 88 & 10.4 & 64 & 5.2 \\
\hline 13 & 3200 & 440 & 393 & 52 & 286 & 26 \\
\hline 14 & 1200 & 156 & 147 & 13 & 108 & 13 \\
\hline 15 & 1600 & 200 & 191 & 26 & 139 & 13 \\
\hline 16 & 2600 & 340 & 302 & 26 & 220 & 26 \\
\hline 17 & 1400 & 182 & 169 & 13 & 124 & 13 \\
\hline 18 & 1900 & 240 & 224 & 26 & 164 & 13 \\
\hline 19 & 2300 & 340 & 291 & 26 & 213 & 26 \\
\hline 20 & 1000 & 142 & 130 & 13 & 96 & 26 \\
\hline 21 & 2400 & 340 & 302 & 26 & 220 & 6.3 \\
\hline 22 & 978 & 127 & 125 & 19 & 91 & 13 \\
\hline 23 & 1300 & 182 & 161 & 13 & 118 & 13 \\
\hline 24 & 1900 & 260 & 232 & 26 & 169 & 13 \\
\hline 25 & 1400 & 194 & 171 & 26 & 125 & 26 \\
\hline 26 & 3600 & 440 & 399 & 52 & 290 & 52 \\
\hline 27 & 4600 & 580 & 520 & 52 & 378 & 13 \\
\hline 28 & 1000 & 142 & 132 & 13 & 96 & 52 \\
\hline 29 & 4500 & 580 & 558 & 147 & 132 & 404 \\
\hline 30 & 1200 & 168 & 191 & 26 & 108 & 139 \\
\hline 31 & 1600 & 200 & 527 & 310 & 26 \\
\hline 32 & 3700 & 500 & 427 & 52 & \\
\hline
\end{tabular}

(1) Maximum concentration of $0.51 \mathrm{ppm}$.

(2) Maximum concentration of $27.0 \mathrm{ppm}$.

(3) Maximum concentration of $50.0 \mathrm{ppm}$.

\section{ANALYSIS AND DISCUSSION OF RESULTS}

With the development of techniques and tactics of construction of the industrial plant, it is seen that today has a great apparatus in our favor. Therefore, proceeding to expose simulations in scenarios where it will constitute exact characteristics of the plant and the place where it will have the procedure with toxic substances is a real fact in which we will be ahead of accidents involving leaks and prepared to this event if it occurs. With this, advancing using the right tools like software, simulating scenarios of the place is a solution that will minimize the hazards and the main involved in the handling of this harmful substance that in this study, the hydrogen sulfide, that is found in the extraction from refining oil to storage. Thus, simulations were carried out in several scenarios with the gas and their respective classifications of the risk index.

The reference mass (MR) is defined (in $\mathrm{kg}$ ) for each of the hazardous substances as presented in the manual. This mass can be understood as the smallest amount of the substance capable of causing damage at a certain distance from the point of release, which in this case is $100 \mathrm{~kg}$ for both the preliminary and the conclusive analyzes. The accidentally released mass is the chemical mass of the substance in the tank/cylinder that together with the lowest vulnerability distance were taken from related studies, but may be different depending on the scenario being studied. Moving on to the analysis of the conclusive scenarios used in the statistical treatment, the following variables are obtained. In the simulated scenarios cylinders were used for storage of the test substance, in which the workers will be in direct contact with the agent. Being a determining factor considered in the choice of the shortest distance for the calculation of the Distance Factor. The masses accidentally released in the calculation of the Hazard Factor vary according to the size of the cylinder and the leakage orifice. Table 6 presents the variables mentioned above.After calculations of FD and FP, the IR Risk Ratios have been obtained from the following scenarios, shown in Table 7 below:

Table 6: Factors used in the equations for the calculation of IR for simulations of statistical treatment

\begin{tabular}{|l|l|l|l|l|l|l|l|}
\hline $\begin{array}{l}\text { Scenar } \\
\text { io }\end{array}$ & D & MLA & MR & $\begin{array}{l}\text { Scenar } \\
\text { io }\end{array}$ & D & MLA & MR \\
\hline 01 & 20 & 44.4 & 100 & 17 & 20 & 106 & 100 \\
\hline 02 & 20 & 37.9 & 100 & 18 & 20 & 99.3 & 100 \\
\hline 03 & 20 & 37.9 & 100 & 19 & 20 & 99.3 & 100 \\
\hline 04 & 20 & 44.4 & 100 & 20 & 20 & 106 & 100 \\
\hline 05 & 20 & 43.8 & 100 & 21 & 20 & 101 & 100 \\
\hline
\end{tabular}




\begin{tabular}{|l|l|l|l|l|l|l|l|}
\hline 06 & 20 & 37.5 & 100 & 22 & 20 & 84.2 & 100 \\
\hline 07 & 20 & 37.5 & 100 & 23 & 20 & 84.2 & 100 \\
\hline 08 & 20 & 43.8 & 100 & 24 & 20 & 101 & 100 \\
\hline 09 & 20 & 355 & 100 & 25 & 20 & 841 & 100 \\
\hline 10 & 20 & 382 & 100 & 26 & 20 & 870 & 100 \\
\hline 11 & 20 & 382 & 100 & 27 & 20 & 870 & 100 \\
\hline 12 & 20 & 355 & 100 & 28 & 20 & 841 & 100 \\
\hline 13 & 20 & 351 & 100 & 29 & 20 & 807 & 100 \\
\hline 14 & 20 & 378 & 100 & 30 & 20 & 836 & 100 \\
\hline 15 & 20 & 378 & 100 & 31 & 20 & 836 & 100 \\
\hline 16 & 20 & 351 & 100 & 32 & 20 & 807 & 100 \\
\hline
\end{tabular}

Table 7: IR Index values for the conclusive scenarios.

\begin{tabular}{|l|l|l|l|l|l|l|l|}
\hline $\begin{array}{l}\text { Scen } \\
\text { ario }\end{array}$ & IR & $\begin{array}{l}\text { Scen } \\
\text { ario }\end{array}$ & IR & $\begin{array}{l}\text { Scen } \\
\text { ario }\end{array}$ & IR & $\begin{array}{l}\text { Scena } \\
\text { rio }\end{array}$ & IR \\
\hline 01 & 1.11 & 09 & 8.9 & 17 & 2.65 & 25 & 21 \\
\hline 02 & 0.95 & 10 & 9.5 & 18 & 2.50 & 26 & 21.8 \\
\hline 03 & 0.95 & 11 & 9.5 & 19 & 2.5 & 27 & 21.8 \\
\hline 04 & 1.11 & 12 & 8.9 & 20 & 2.7 & 28 & 21 \\
\hline 05 & 1.1 & 13 & 8.8 & 21 & 2.5 & 29 & 20.2 \\
\hline 06 & 0.93 & 14 & 9.4 & 22 & 2.1 & 30 & 20.9 \\
\hline 07 & 0.94 & 15 & 9.4 & 23 & 2.1 & 31 & 21 \\
\hline 08 & 1.1 & 16 & 8.8 & 24 & 2.5 & 32 & 20 \\
\hline
\end{tabular}

In the application of the Industrial Risk Analysis Study for the installation of warehouses or facilities that handle with the hydrogen sulfide it was observed that in the studied scenarios it has all the categories of risk according to each simulation. The amount of gas stored in the facilities containers and the distance from the vulnerable areas were decisive for these results. In the calculations, the areas immediately outside the industry boundaries for the preliminary scenarios and the direct contact of the worker with the cylinder for the concluding scenarios were considered as vulnerable areas. Thus, the requirements for obtaining the various licenses: prior, installation and operation are a function of the risk category. That depending on the value of your index will be charged certain measures.

Considering the scenarios obtained, it can be seen from the radial graphs that the area represented by the yellow line indicates that the reference value for the gas with a 60 minute exposure time for AEGL-1 is $0.51 \mathrm{ppm}\left(0.71 \mathrm{mg} / \mathrm{m}^{3}\right)$ above which it is expected that the general population, including susceptible individuals, may experience irritation with no serious or irreversible effects in the long run. The area bounded by the orange line indicates that the reference value for the gas with 60-minute exposure time for AEGL-2 is $27 \mathrm{ppm}\left(39 \mathrm{mg} / \mathrm{m}^{3}\right)$, above that concentration it is expected that the general population, may experience serious long-term or irreversible effects with the impairment of its ability to escape. For the area represented by the red line indicates that the reference value for the gas with a 60 minute exposure time for AEGL-3 is $50 \mathrm{ppm}\left(71 \mathrm{mg} / \mathrm{m}^{3}\right)$, above that concentration it is expected that the population in general, including susceptible individuals may experience life-threatening effects.

\section{CONCLUSION}

The objective of this research was to develop a study of the consequence analysis of leaks involving hydrogen sulfide in petroleum refining. Toxic substance that in contact with man leads to death in a matter of minutes. In this research, the importance of clarification about the toxicity of $\mathrm{H}_{2} \mathrm{~S}$ in industrial processes and its consequences on human health is shown in the research. The consequence analysis was carried out with the help of ALOHA software, which allowed the calculation and the realization of graphs, with the modeling of the clouds of toxic gas accidentally released.

The results obtained in this work are satisfactory and useful, especially for the industry in terms of forecasting and emergency planning, in strengthening the existing safety management. The results showed that in addition to the possibilities for system improvement measures, the training of all refinery employees in all sectors is indispensable in the emergency response. Operators who handle and control the hydrogen sulfide removal system are the members with the immediate responsibility for the performance and response to a hydrogen sulfide leak emergency. The theoretical and practical training with simulations predicting the scenarios raised in this research will be fundamental in reducing the severity of the risk.

Thus, it is concluded that there are significant risks associated with the installations of hydrogen sulfide storage vessels in refineries, since they are facilities that may be located close to the urban environment which represent many vulnerable areas. From the results obtained by the ALOHA, it was verified that the scenarios 27 and 29 present greater risks, because of the reach of its toxic clouds in relation to the other simulations, in that in the scenario 27 reaches in the AEGL-1 a range of $4600 \mathrm{~m}$, in AEGL-2 520 $\mathrm{m}$ in AEGL-3 $378 \mathrm{~m}$ and in scenario 29 it reaches a range of $4500 \mathrm{~m}$ in AEGL-2 $558 \mathrm{~m}$ in the AEGL-3 $404 \mathrm{~m}$, showing a great danger to surrounding areas and the employees of the industry. These risks must be managed appropriately to reduce the consequences of possible accidents that may occur. It is incumbent upon industries to conduct a more detailed study to realistically estimate the likelihood of failure of equipment in refining facilities in order to reduce uncertainties and weaknesses in order to develop an internal management system aimed at protecting man, environment and heritage.

\section{ACKNOWLEDGMENT}

The first author thanks Brazilian National Council for Scientific and Technological Development (CNPq-PIBITI) for the financial assistance received. 


\section{REFERENCES}

[1]. Bhattacharya R, Kumar VG. Consequence analysis for catastrophic explosion of solvent storage tank - a case study. International journal of chemtech research, v. 8, n.4, India, 2015.

[2]. Bundschuh J, Maity JP. Geothermal Arsenic: occurrence, mobility and environmental implications. Renewable and Sustainable Energy Reviews. v. 42, p. 12141222, fev. 2015.

[3]. Conama. "Resolução no 357/2005". Ministério do MeioAmbiente, ConselhoNacional de MeioAmbiente. Brasília, 2005.

[4]. Fepam. Manual de Análise de RiscosIndustriais. Projeto de Manual de Análise de RiscoMarço, 2001.

[5]. Gouveia F. Tecnologianacional para extrairpetróleo e gás do pré-sal. Conhecimento\&Inovação, v.6, n.1, Campinas-SP, 2010.

[6]. Jones K. Case studies of hydrogen sulphide occupational exposure incidents in the UK. Toxicology letters, v. 231, n. 3, p. 374-7, 15 dez. 2014.

[7]. Kavishwar SM, Chatpalliwar AS. Chatpalliwar. Consequence analysis of liquefied ammonia leakage accident with Aloha - simulation and off-site emergency scenario. Research J. Engineering and Tech. 4(2): AprilJune, 2013 page 84-89.

[8]. Mainier FB, Rocha AA. $\mathrm{H}_{2} \mathrm{~S}$ : novasrotas de remoçãoquímica e recuperação de enxofre. In: congressobrasileiro de P\&D emPetróleo\&Gás, v.2, Niterói RJ, 2003.

[9]. Mainier FB, Sandres GC, Tavares SSM. Corrosãoporsulfeto de hidrogênio $\left(\mathrm{H}_{2} \mathrm{~S}\right)$ e suasimplicações no meioambiente e nasegurança industrial. In: CongressoIberoamericano de EngenhariaMecânica, v.8, Cusco, 2007.

[10]. Mainier FB, Viola EDM. O sulfeto de hidrogênio $\left(\mathrm{H}_{2} \mathrm{~S}\right)$ e o meioambiente. In: SIMPÓSIO DE EXCELÊNCIA EM GESTÃO E TECNOLOGIA, v.2, Resende - Rio de Janeiro, 2005.

[11]. Nascimento CAO, Moro 1FL. Petróleo: energia do presente, matéria-prima do futuro? Rev. USP, $n^{\circ} .89$, São Paulo, mar./maio 2011.

[12]. Palazzi E et al., 1982. "Diffusion from a Steady Source of Short Duration." Atmospheric Environment. v.16 (12):2785 - 2790.

[13]. Tseng JM, Su TS, Kuo CY. Consequence evaluation of toxic chemical releases by ALOHA. International Symposium on Safety Science and Technology, v.45, China, 2012.

[14]. Werner AK. et al. Environmental health impacts of unconventional natural gas development: A review of the current strength of evidence. The Science of the total environment, v. 505C, n. x, p. 1127-1141, 1 mar. 2015. 